\title{
The classification of patients with chronic pain: Age and sex differences
}

\author{
Andrew J Cook PhD, Dania C Chastain PhD
}

\section{AJ Cook, DC Chastain.}

The classification of patients with chronic pain: Age and sex differences.

Pain Res Manage 2001;6(3):142-151.

OBJECTIVE: To further develop an empirically based classification system for chronic pain patients through the examination of age and sex differences, and incorporation of pain duration in the grouping algorithm.

SUBJECTS: Three hundred seventy-four chronic pain patients (300 aged 13 to 59 years; 74 aged 60 to 89 years) assessed at an outpatient, multidisciplinary pain management centre.

METHODS: Patients completed measures of demographic and descriptive information, pain intensity (box rating scale), perceived disability (modified Pain Disability Index) and affective distress (Symptom Checklist-90 Revised) before multidisciplinary treatment. Standardized scores from the assessment measures were entered into a series of hierarchical, multivariate cluster analyses to identify underlying patient subgroups.

RESULTS: Age-based patient groupings from prior research were partially replicated. Significant differences in clinical presentations were observed across age and sex groups. Pain duration was found to make an important contribution to the patient groupings. 'Good control' (low pain, disability, distress) and variants of 'chronic pain syndrome' (elevated pain, disability, distress) groupings were identified across all analyses. Two variants of a 'stoic' profile were identified among older patients, with low levels of distress relative to pain and perceived disability. One of these profiles was associated with long pain duration and was found only among males. Several unique clinical profiles were identified for female patients.
CONCLUSIONS: There are important age and sex differences in the clinical presentations of chronic pain patients. Some older patients present with unique clinical profiles that may reflect cohort differences, and/or physiological or psychological adjustment processes. There appears to be a greater number of distinct chronic pain presentations among females. Research on the classification of chronic pain patients within homogeneous diagnostic subgroups is needed.

Key Words: Age; Chronic pain; Classification; Pain duration; Sex

\section{Classification des patients atteints de douleur chronique : Différences liées à l'âge et au sexe}

OBJECTIF : Raffiner un système de classification empirique à l'intention des patients souffrant de douleur chronique par l'examen des différences liées à l'âge et au sexe et l'intégration de la durée de la douleur dans l'algorithme de classification.

SUJETS : Trois cent soixante-quatorze patients atteints de douleur chronique (300 âgés de 13 à 59 ans et 74 âgés de 60 à 89 ans) évalués dans une clinique externe pluridisciplinaire consacrée au traitement de la douleur.

MÉTHODES : Les patients ont répondu à un questionnaire portant sur des éléments démographiques et descriptifs, sur l'intensité de la douleur (échelle d'évaluation) invalidité perçue (indice modifié de l'invalidité causée par la douleur) et la détresse émotionnelle (questionnaire Symptom Checklist-90 révisé) avant un traitement pluridis-

voir page suivante 
ciplinaire. Les indices standardisés à partir des mesures évaluées ont été intégrés à une série d'analyses hiérarchiques multivariées par grappes afin d'identifier certains sous-groupes de patients.

RÉSULTATS : Les regroupements selon l'âge établis lors de projets de recherche antérieurs ont, en bonne partie été reproduits. Des différences significatives ont été observées sur le plan des tableaux cliniques selon l'âge et le sexe. La durée de la douleur s'est révélée être un important facteur contributif à la formation des groupes. Les groupes «bien contrôlés» (douleur, invalidité et détresse faibles) et des variantes du syndrome de la douleur chronique (douleur, invalidité, détresse intenses) ont pu être identifiés dans toutes les analyses. Deux variables du profil stoïque ont été recensées chez les patients plus âgés, avec des taux faibles de détresse par rapport à la douleur et par rapport à l'invalidité perçue. L'un de ces profils a été associé à une douleur de longue date et n'a été observé que chez les hommes. Plusieurs profils cliniques uniques ont été identifiés chez les patientes.

CONCLUSION : Il existe d'importantes différences selon l'âge et le sexe entre les tableaux cliniques de la douleur chronique. Certains patients plus âgés présentent des profils cliniques uniques qui peuvent refléter des différences de cohorte et/ou des processus d'adaptation physiologiques ou psychologiques. Il semble y avoir un plus grand nombre de tableaux cliniques de douleur chronique distincts chez les femmes.
$\mathrm{T}$ he nature and extent of differences in the chronic pain experience of older adults remain somewhat of a mystery. Awareness of such differences is important to the assessment and treatment of pain in this age group. Chronic pain is known to be highly prevalent in older adults (1), and existing data suggest that it is undertreated (2). Painful conditions such as degenerative musculoskeletal disease (eg, rheumatoid arthritis, osteoporosis) and some neuropathies (eg, postherpetic neuralgia, diabetic neuropathies) occur more commonly in older patients. However, potential differences in clinical manifestations of chronic pain in different age groups are unclear.

Some of the first age comparisons of clinical pain presentations suggested that similarities among younger and older chronic pain patients outweighed the differences. Middaugh et al (3) compared small samples of older (55 to 78 years) and younger (29 to 48 years) patients presenting to a multidisciplinary chronic pain rehabilitation program (CPRP). Older patients were found to have higher levels of health care utilization, lower productive physical activity and higher intake of pain-related medication. However, the two age groups did not significantly differ on other measures, including pain ratings, walking tolerance, and symptoms of emotional and cognitive distress. Sorkin et al (4) compared clinical presentations of younger (35 years and younger) and older (65 years and older) patients attending a multidisciplinary CPRP. They found no significant differences in measures of self-reported activity, pain severity, life interference or emotional functioning. Older patients reported using fewer cognitive pain coping strategies and had more frequent significant findings on medical/physical tests. A study of the use of cognitive and behavioural pain coping strategies across four age groups of chronic pain patients revealed no significant age differences in either their use or perceived effectiveness (5).

Subsequent studies have addressed age comparisons across a wide range of patient samples and clinical variables. They have supported the many similarities in clinical presentations across age groups but have highlighted some meaningful differences. There is some evidence for higher levels of physical impact (6), lower levels of anxiety $(6,7)$, a stronger correlation between pain severity and depression (8), and more external locus of control beliefs $(9,10)$ in older chronic pain patients. A comparison of pain experi- ence and response across three age groups (18 to 44 years, 45 to 64 years and 65 to 85 years) in a very large pain clinic sample revealed that older patients reported less emotional response to pain and fewer pain behaviours than the two younger age groups, and had the weakest association between emotional responses and pain behaviour (11). Another age analysis of patients treated at a CPRP reported that older patients (65 to 79 years) had more favourable scores on 27 of 43 self-report rating scales at initial assessment than patients in younger (21 to 44 years) or middle (45 to 64 years) age groups (12). The authors did not report which of the assessed domains were rated more favourably by the older patients.

A different perspective on age differences in clinical pain presentation is provided by identification of patient subgroupings through the statistical procedure of hierarchical cluster analysis (13). This is a multivariate technique that attempts to identify homogenous subgroups of cases by grouping them based on similarities on identified variables. It has been used to identify such groupings of patients with chronic pain based on multidimensional assessments, measures of pain behaviours and tests of psychological functioning (14-18). Klapow et al (19) employed cluster analytical procedures to identify three distinct clinical presentations of patients with low back pain (ages 21 to 64 years) based on three dimensions: pain, health-related impairment and depression. The identified groups were 'chronic pain syndrome' (high levels of pain, impairment and depression), 'good pain control' (low levels of pain, impairment and depression) and 'positive adaptation to pain' (high levels of pain with low levels of impairment and depression). These three patient groupings were cross-validated in an independent pain clinic sample, and were found to be stable across time for a subsample of patients re-assessed after a sixmonth interval.

Corran et al (13) extended these findings through hierarchical cluster analyses of older (66 years and older) and younger (65 years and younger) pain patients presenting to two pain clinics in Australia. They identified several distinct clinical presentations of patients in the two age samples. The three patient subgroups of Klapow et al (19) were replicated in their younger patient group. However, in the older patient group the 'chronic pain syndrome' subgroup was replaced by a 'high impact' cluster (low pain, high impair- 
ment, high depression). The authors speculated that the existence of the unique 'high impact' typology in the older patient group could be the result of factors such as increasing prevalence of multiple disease states (affecting either pain or its consequences), or age differences in pain attributions and coping styles. They also observed from a separate cluster analysis of the full patient sample that each of the patient subgroupings was found in both age groups, although the 'chronic pain syndrome' pattern was predominantly a younger patient phenomenon, while the 'high impact' pattern occurred predominantly in the older patients. They called for further studies to investigate factors contributing to the 'high impact' clinical presentation among older pain patients.

The purpose of the present study was to attempt a replication of the findings of Corran et al (13) in a cross-cultural pain clinic sample using different assessment strategies, and to extend their analyses by incorporating pain duration as a clustering variable, and evaluating sex differences in the clustering of chronic pain patients. As a statistical technique, cluster analysis is very sensitive to the variables included. Both omission of important variables and inclusion of extraneous variables can significantly affect the results of the analysis $(20,21)$. Pain duration is known to be an important factor in the development of chronic pain syndromes. Available data suggest a pattern of declining psychosocial adjustment with the transition from acute to early and late chronic pain (22). Pain duration has been shown to be significantly related to many aspects of the chronic pain experience (23), and relationships between subjective pain experience and pain behaviour have been shown to become stronger with increased duration of chronic pain (24). The relationship between pain duration and age varies across patient samples and, therefore, cannot be assumed. For example, Corran et al (13) reported no significant difference in mean pain duration across their age groups. Omission of this variable from cluster analyses of chronic pain patients may result in invalid or incomplete groupings due to failure to differentiate patients with significantly different clinical presentations.

Sex differences in pain experience and responses are well documented $(25,26)$. These include differences in perception and response to experimentally induced pain, prevalance of pain symptoms and specific chronic pain conditions, associated health care utilization and reported use of pain coping strategies. Additionally, sex differences in the classification of chronic pain patients via clustering methodologies have been reported (17). The clinical significance of sex differences in pain remains unclear $(25,26)$.

\section{Subjects}

Data were obtained from 399 patients treated at a university hospital-based, multidisciplinary pain centre. Twenty-five patients $(6 \%)$ with missing data on one or more of the dependent variables were excluded from the analyses, leaving a final sample of 374 . These patients did not differ sig- nificantly from the remaining subjects on any of the demographic or descriptive variables. The majority of the subjects were female $(66 \%)$, married (54\%), had a high school or college education $(76 \%)$, were currently not working $(70 \%)$, and had pain in the low back/sacral area $(25 \%)$, lower limbs (10\%), head/face/mouth $(7 \%)$ or a combination of major body sites (33\%) (based on classification system of the International Association for the Study of Pain), with an average duration of 5.6 years. The most common pain diagnostic categories based on pain centre evaluations were neuropathic $(29 \%)$, myofascial $(14 \%)$, mechanical $(10 \%)$, other musculoskeletal (11\%) and multiple etiologies $(25 \%)$. The sample comprised 300 subjects in the 13 to 59 years age range (mean \pm SD $40.5 \pm 9.9$ ) and 74 subjects in the 60 to 89 years age range $(69.6 \pm 7.7) \cdot \chi^{2}$ comparisons by age group revealed significant differences $(\mathrm{P}<0.001)$ for marital and employment status, but no significant differences for other demographic variables. There were more divorced, separated or widowed, and retired subjects in the older group, and more single, employed and disabled subjects in the younger group.

\section{Procedure}

Patients were mailed a demographic, pain and functioning questionnaire package after scheduling their initial visit at the pain management centre. Completed forms were brought to their clinic appointment, and those who failed to complete the forms were asked to do so at the time of their clinic visit.

\section{Measures}

Demographic and descriptive information were obtained from a patient assessment inventory. The assessment package also included self-rated measures of pain description and intensity, pain disability and cognitive/emotional functioning. Pain intensity ratings were obtained with 0 to 10 box scales. Box scales, which combine features of numerical rating scales and visual analogue scales, have been shown to be reliable and valid measures of pain intensity, and to be strongly correlated with a composite pain intensity measure (27). They have high compliance rates, and have been found to be easier for older patients to complete than the visual analogue scale (28). As with numerical rating scales, box scale scores can be treated as ratio data in statistical analyses (27). Patient ratings of average pain intensity for the past week were used in the analyses.

A modified version of the Pain Disability Index (PDI) (29) was used to measure perceived pain-related impairment of functioning. On the PDI, patients rate the degree to which they believe that their pain interferes with seven areas of daily functioning. It has been found to be an internally consistent and moderately reliable measure of perceived disability (30), with good discriminative ability in various patient populations (31). An earlier version of the PDI has been employed in the authors' pain clinic setting, due to its specificity and clinical utility. In contrast to the seven functional areas assessed on the PDI, it obtains ratings for nine 
areas: work, household chores, yardwork or shopping, social, recreational, sexual, physical exercise, sleep and personal hygiene. Patients rate perceived interference from pain for each area on a scale of 1 to 5, producing a total score range of 9 to 45 . This perceived disability scale has been found to have high internal consistency with individual item ratings loading prominently on a single underlying factor, consistent with the PDI (30). To correct for occasional omitted items on the questionnaire, an averaged score was obtained by dividing the total score by the number of items completed.

Cognitive and emotional functioning were assessed with the Symptom Checklist 90-Revised (SCL-90R), a 90-item self-report measure that produces nine scale scores of psychological disturbance (32). Validity and reliability have been well established with psychiatric patient and nonpatient samples (32). The SCL-90R and its predecessor (SCL-90) have been used extensively as clinical and research measures with chronic pain patients $(33,34)$, and for identifying chronic pain patient typologies based on hierarchical cluster analyses $(16,17)$. Chronic pain patients have been found to have different response patterns on the SCL-90R compared with psychiatric patients and nonpatients ('normals') (34); therefore, empirically based scoring methods for chronic pain patients have been developed $(33,34)$. The scale scores developed by Shutty et al (33) based on exploratory and confirmatory factor analyses with chronic pain patients were used in this study. The 'anxious depression' factor scale was used as the dependent variable for mood disturbance because it includes symptoms of depression and anxiety commonly seen in patients with chronic pain. The factor scale for 'cognitive depression' was not included, due to its high correlation with this scale $(\mathrm{r}=0.79)$. Second-order factor analysis of the SCL-90R factor scales has indicated a small number of underlying factors, consistent with findings for other multiscale measures of psychological disturbance (33).

\section{Statistical analyses}

For age comparisons, the sample was divided into two age groups: under 60 years, and 60 years and older. Because the patient sample was highly skewed toward the younger ages, 60 years was chosen as the dividing point for the age comparisons. The establishment of a cutoff point for 'old age' is recognized as arbitrary, and has commonly been derived from social policy decisions (35). A MANOVA using the general linear model and Wilk's lambda criterion was employed for an age group comparison of the four dependent variables. Subsequently, hierarchical multivariate cluster analyses were performed independently for the two age groups using the three dependent variables from prior research $(13,19)$ : pain (rating of average pain intensity), functional impact (modified PDI score) and affective distress (SCL-90R anxious-depression factor score). Because cluster analyses in some datasets are sensitive to differences in scaling of variables (20), all variables were normalized with z-score transformations. Ward's minimum variance
TABLE 1

Scores (mean \pm SD) for dependent variables by age group

\begin{tabular}{lcc}
\hline Variable & $\begin{array}{c}\text { Patients aged 13-59 } \\
\text { years }(\mathbf{n}=\mathbf{3 0 0})\end{array}$ & $\begin{array}{c}\text { Patients age 60-89 } \\
\text { years }(\mathbf{n}=\mathbf{7 4})\end{array}$ \\
\hline Pain intensity $(0-10)$ & $7.2 \pm 2.0$ & $7.5 \pm 1.8$ \\
$\begin{array}{l}\text { Perceived disability } \\
(1-5)\end{array}$ & $3.6 \pm 0.90$ & $3.7 \pm 0.86$ \\
$\begin{array}{l}\text { SCL-90R anxious } \\
\text { depression }\end{array}$ & $10.0 \pm 7.2$ & $7.9 \pm 6.2^{*}$ \\
$\begin{array}{l}\text { Pain duration (years) } \\
\text { *P<0.05***P<0.001. SCL-90R Symptom Checklist } 90-\text { Revised }\end{array}$
\end{tabular}

method (36) for hierarchical clustering was employed with the squared Euclidian distance criterion. This method has consistently been shown to be a reliable approach to recovering underlying clusters $(20,21,37)$.

A multiple-objective criterion approach was employed to determine the number of underlying clusters to retain. The importance of this determination and the inherent challenges involved have begun to be recognized by pain researchers (38), although unreliable and invalid methods have frequently been reported in the pain literature. Empirical evaluations of the available criteria have identified several of the most robust (39). Nonetheless, due to the variable performance of such criteria in different types of data sets, a multiple statistical criteria approach has been recommended (39). Therefore, consensus among the pseudo F (40), pseudo t ${ }^{2}$ (41) and cubic clustering criterion (42) statistics was used to determine the number of clusters to retain in each analysis.

A second set of hierarchical cluster analyses was performed by age group, with the addition of the pain duration variable. Sex comparisons were not possible by age group, due to inadequate numbers in the older patient group $(n=18$ males). Therefore, a sex comparison was undertaken in a final set of cluster analyses on the full age sample of subjects. Significance tests for mean differences between cluster groupings (eg, ANOVA, MANOVA) or discriminant analysis have been used in previous cluster analyses of chronic pain patients to validate identified clusters $(13,16,19)$. However, these tests are invalid due to substantial violation of the assumptions of both parametric and nonparametric tests for groups identified through cluster analyses $(21,39)$. ANOVAs were employed to evaluate age differences for the clusters identified among male and female subjects because age was not a clustering variable. The Games-Howell multiple comparison test was employed for post hoc comparisons, with homogeneity of variances not assumed.

\section{RESULTS}

The MANOVA on pain, disability and distress scores by age group revealed a significant main effect $(\mathrm{F}=6.9, \mathrm{P}<0.001)$. The dependent variables were considered to have equal 


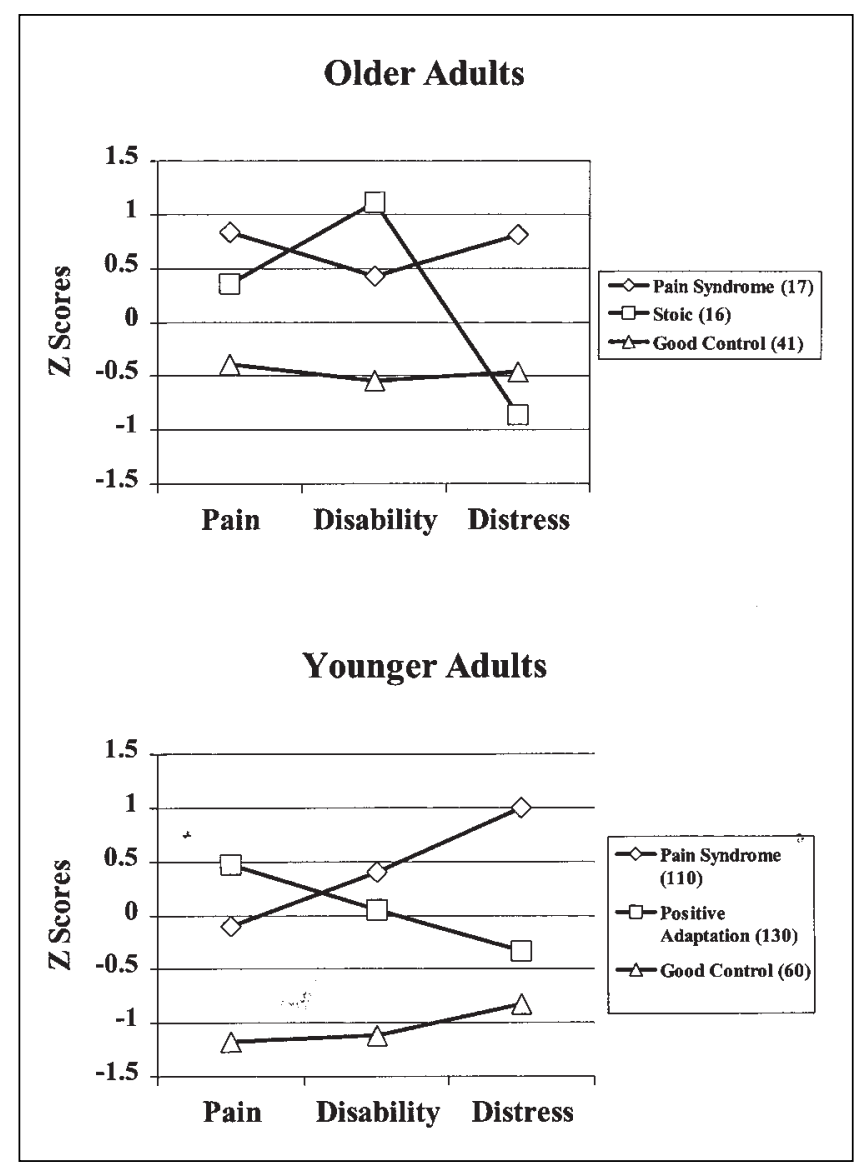

Figure 1) Cluster groupings of younger (aged 13 to 59 years) and older (aged 60 to 89 years) patients based on standardized scores for pain intensity, perceived disability and affective distress

importance in the multivariate analysis; therefore, group differences in individual variables were evaluated with univariate ANOVAs. The results indicated that the older patient group reported less distress $(\mathrm{F}=5.7, \mathrm{P}=0.02)$ and pain of longer duration $(\mathrm{F}=18.7, \mathrm{P}<0.001)$ (Table 1). Bonferroni adjustment of significance level for multiple comparisons was employed. The strength of the relationships between age group and both pain duration and distress scores was weak, with only $5 \%$ and $2 \%$ of the respective variances being accounted for by age group.

In the first set of cluster analyses based on the threesymptom paradigm from prior research, convergence of the multiple indicator criteria suggested a three-cluster solution in both the younger and older age groups. The cluster solutions are shown in Figure 1. For the younger group, the three clusters reported by Corran et al (13) and Klapow et al (19) were quite closely replicated, and were similarly labelled 'good control', 'positive adaptation to pain' and 'chronic pain syndrome'. The latter group differed slightly from the previously published findings in that the average pain intensity rating for this subgroup was below the full group average. The cluster solution for the older group (Figure 1) replicated only the 'good control' cluster from Corran et al (6). The other identified clusters were 'chronic pain syn-



Figure 2) Cluster groupings of younger (aged 13 to 59 years) and older (aged 60 to 89 years) patients, with pain duration added as a clustering variable

drome', and a cluster characterized by above average levels of pain and disability, but very low levels of distress, labelled 'stoic'.

In the next set of cluster analyses, the pain duration variable was added. Although duration of pain was significantly higher in the older patient group (Table 1), the correlation between age and pain duration was weak $(\mathrm{r}=0.25$, Spearman's rho $=0.18$ ), indicating that less than $7 \%$ of the variance in pain duration was accounted for by age. In both the younger and older patient groups, four clusters were retained based on the multiple criteria approach. In both groups, the pain duration variable significantly altered the cluster solution. In the older group the 'good control' and 'stoic' clusters were maintained - both with near average lengths of pain duration (Figure 2). A cluster with high levels of pain and distress, and average disability ratings was extracted. This subgroup had the lowest average pain duration and was labelled 'chronic pain syndrome (early)'. The fourth cluster represented a small group of patients $(n=6)$ with very long pain duration coupled with near average levels of pain and disability, and low levels of distress. This group was labelled 'stoic - prolonged pain'. In the younger group, the 'chronic pain syndrome' and 'good control' clusters from prior research were replicated, both groups having 
TABLE 2

Mean unstandardized scores on dependent variables for the older cluster groupings (patients aged 60 to 89 years)

\begin{tabular}{lcccc}
\hline Variable & $\begin{array}{c}\text { Pain syndrome } \\
\text { (early) }\end{array}$ & Stoic & $\begin{array}{c}\text { Stoic } \\
\text { (prolonged) }\end{array}$ & $\begin{array}{c}\text { Good } \\
\text { control }\end{array}$ \\
\hline Age (years) & & & & \\
Mean \pm SD & $67.6 \pm 7.4$ & $68.7 \pm 8.8$ & $70.6 \pm 6.6$ & $71.5 \pm 7.2$ \\
Median & 64 & 65 & 71.5 & 71.5 \\
$\begin{array}{c}\text { Pain duration } \\
\text { (years) }\end{array}$ & $3.3 \pm 3.8$ & $10.5 \pm 9.4$ & $47.3 \pm 8.9$ & $5.0 \pm 6.0$ \\
$\begin{array}{c}\text { Pain intensity } \\
\text { (0-10) }\end{array}$ & $8.7 \pm 0.8$ & $8.3 \pm 1.5$ & $7.7 \pm 1.5$ & $5.8 \pm 1.4$ \\
$\begin{array}{c}\text { Perceived } \\
\text { disability (1-5) }\end{array}$ & $3.6 \pm 1.0$ & $4.5 \pm 0.4$ & $3.6 \pm 0.5$ & $3.2 \pm 0.7$ \\
$\begin{array}{c}\text { SCL-90R } \\
\text { Anx/Depn }\end{array}$ & $15.0 \pm 4.1$ & $4.6 \pm 3.3$ & $3.0 \pm 2.8$ & $5.8 \pm 5.1$ \\
\hline
\end{tabular}

Anx/Depn Anxious depression; SCL-90R Symptom Checklist-90 Revised

TABLE 3

Mean unstandardized scores on dependent variables for the younger cluster groupings (patients aged 13 to 59 years)

\begin{tabular}{lcccc}
\hline & $\begin{array}{c}\text { Pain } \\
\text { syndrome }\end{array}$ & $\begin{array}{c}\text { Moderate } \\
\text { (prolonged) }\end{array}$ & Moderate & $\begin{array}{c}\text { Good } \\
\text { control }\end{array}$ \\
\hline Age (years) & & & & \\
Mean \pm SD & $39.4 \pm 8.5$ & $45.3 \pm 7.0$ & $40.6 \pm 9.9$ & $39.2 \pm 10.8$ \\
Median & 39 & 46.5 & 41 & 39.5 \\
$\begin{array}{l}\text { Pain duration } \\
\text { (years) }\end{array}$ & $4.2 \pm 4.3$ & $24.8 \pm 6.9$ & $2.6 \pm 2.6$ & $2.9 \pm 3.0$ \\
$\begin{array}{l}\text { Pain intensity (0-10) } \\
\text { Perceived }\end{array}$ & $8.4 \pm 1.1$ & $7.1 \pm 2.0$ & $7.7 \pm 1.7$ & $5.5 \pm 1.9$ \\
$\begin{array}{c}\text { disability (1-5) } \\
\text { SCL-90R }\end{array}$ & $4.2 \pm 0.6$ & $3.6 \pm 0.8$ & $4.0 \pm 0.5$ & $2.5 \pm 0.6$ \\
Anx/Depn & $23.1 \pm 3.1$ & $10.9 \pm 7.4$ & $9.1 \pm 5.1$ & $5.4 \pm 4.5$ \\
\hline
\end{tabular}

Anx/Depn Anxious depression; SCL-90R Symptom Checklist-90 Revised

a near average length of pain duration (Figure 2). Two additional clusters with near average levels of pain, disability and distress were identified - one with a very high pain duration and the other with a slightly below average pain duration. These clusters were labelled 'moderate' and 'moderate - prolonged pain'. Mean unstandardized scores for the dependent variables by cluster groupings are shown in Tables 2 and 3.

The final analyses addressed sex-based clusterings for the full age sample. A significant difference in cluster solutions was found between the sexes. For male subjects, multiple-indicator criteria indicated a four-cluster solution (Figure 3). The identified clusters were the 'chronic pain syndrome', 'good control', 'stoic' and 'stoic - prolonged pain' symptom patterns. As with the older patient sample (Figure 2), the 'stoic - prolonged pain' cluster had a highly

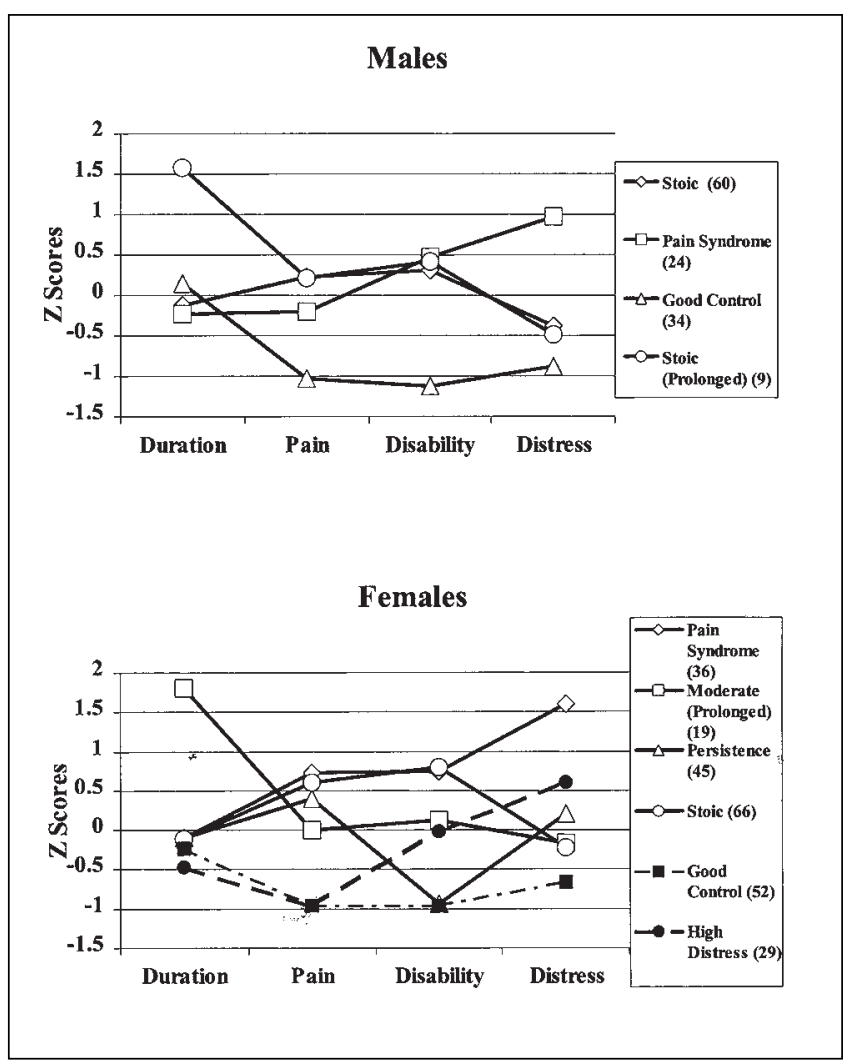

Figure 3) Cluster groupings of female and male patients based on standardized scores for four dependent variables

TABLE 4

Age comparison for male cluster groupings

\begin{tabular}{lcccc}
\hline Variable & Stoic & $\begin{array}{c}\text { Pain } \\
\text { syndrome }\end{array}$ & $\begin{array}{c}\text { Good } \\
\text { control }\end{array}$ & $\begin{array}{c}\text { Stoic } \\
\text { (prolonged) }\end{array}$ \\
\hline Age (years) & & & & \\
Mean \pm SD & $45.3 \pm 13.4$ & $43.9 \pm 14.7$ & $45.1 \pm 11.7$ & $53.1 \pm 9.8$ \\
Median & 42 & 44.5 & 44 & 51 \\
\hline
\end{tabular}

elevated average duration of pain relative to the other subject clusters, but also had an above average level of perceived disability. For female patients, six unique clusters were identified (Figure 3). Three of these were very similar to the male groupings: 'chronic pain syndrome', 'good control' and 'stoic'. A grouping with high average pain duration was identified, with moderate levels of the three symptom variables ('moderate - prolonged pain'), as seen in the younger adult clusterings (Figure 2). Two other unique groupings were identified: 'high distress' (low pain, moderate disability, high distress) and 'persistence' (high pain and distress, very low perceived disability). Age comparisons for the male and female cluster groupings are shown in Tables 4 and 5. ANOVA for age differences in the male sample was not significant, but a significant age difference was found for female subjects $(\mathrm{F}=3.12, \mathrm{P}<0.01)$. Post hoc 
TABLE 5

Age comparison for female cluster groupings

\begin{tabular}{|c|c|c|c|c|c|c|}
\hline Variable & $\begin{array}{c}\text { Pain } \\
\text { syndrome }\end{array}$ & Stoic & $\begin{array}{c}\text { High } \\
\text { distress }\end{array}$ & $\begin{array}{l}\text { Good } \\
\text { control }\end{array}$ & $\begin{array}{c}\text { Moderate } \\
\text { (prolonged) }\end{array}$ & Persistence \\
\hline \multicolumn{7}{|l|}{$\overline{\text { Age (years) }}$} \\
\hline Mean $\pm \mathrm{SD}^{*}$ & $42.0 \pm 12.3$ & $49.6 \pm 15.4$ & $43.4 \pm 15.2$ & $44.0 \pm 17.5$ & $56.3 \pm 14.1$ & $46.7 \pm 16.5$ \\
\hline Median & 39.5 & 47 & 42 & 41.5 & 54 & 44 \\
\hline
\end{tabular}

${ }^{*} F=3.12, P<0.01$

comparisons revealed that subjects in the "moderate - prolonged pain' cluster were significantly older than those in the 'chronic pain syndrome' and 'good control' clusters.

\section{DISCUSSION}

The results of this study have replicated a primary finding of prior research, namely the existence of unique clinical presentations among older chronic pain patients. Our understanding of these important age differences has been extended through the identification of subgroups of older patients with 'stoic' presentations (disproportionately low levels of affective distress). Although lower average levels of distress have been reported for older versus younger adults with chronic pain $(2,7,11,13,43)$, data supporting the presence of a stoic subgroup of older pain patients have not previously been reported. The importance of pain duration to clinical presentation of chronic pain has also been reaffirmed. The inclusion of this variable in the cluster analyses has been shown to better distinguish groupings of chronic pain patients, and to identify important subgroupings across the symptom domains of pain, perceived disability and affective distress. Significant sex differences in patient groupings have also been demonstrated, including the identification of symptom patterns that are unique to both male and female patients with chronic pain. These findings support the importance of sex-related factors in the experience and manifestation of pain.

Stoicism has been discussed as a potential contributor to increased pain thresholds among older adults (44). Although tempered versions of the stoic profile were identified in our analyses of male and female patients across the full age spectrum (mean age 45.3 to 53.1 years), the relative levels of distress were higher. The stoic profile was not identified in the separate analyses for younger pain patients. The closest approximation was the 'positive adaptation' profile using the three-symptom model from prior research, but this grouping was not sustained when pain duration was incorporated. The grouping of younger adults with long pain duration (mean 25 years) had moderate levels of all symptoms (8\% of sample), although slightly less pain and perceived disability than the majority of patients in the moderate group (53\%). There appear to be substantially different patterns of adjustment to chronic pain of lengthy duration, with the stoic profile being more common among older adults. Two subgroupings of this profile were identified among older patients: patients with near average pain duration (mean 10.5 years), moderate pain, high disability and low distress (28\% of subsample); and a small group of patients with very long pain duration (mean 47 years), moderate pain and perceived disability, and very low distress (8\%). Both groups can be characterized as effectively coping or adjusting to their chronic pain, although the second group appears to be more successfully adapted. The very long duration of their pain raises the possibility of a temporal adjustment or habituation process, as has been previously suggested as a factor in adaptation to chronic pain in old age (45). The physiological and/or psychological mechanisms that would account for this type of process have not been established, although age-related changes in pain perception $(43,46)$ could be involved.

Other factors that have been identified as potential contributors to stoicism among older adults (through either developmental or cohort effects) include constriction of emotional range and intensity, bias in willingness to report mood states and tendency to endorse socially acceptable responses (47). Variability in cognitive appraisals and coping attributes must also be considered (48). Stoicism has been identified as an underlying construct among individuals who perceive themselves to be effectively coping with chronic pain, with social acceptance and maintenance of self-esteem as potential contributing factors (49). Age differences in the psychosocial context in which chronic pain is experienced could also be a factor in the findings of this and other studies. The absence of work-related physical and psychological stressors for retired older adults could significantly influence the cognitive, affective and behavioural components of the chronic pain experience. It has been argued that, by definition, stoic individuals should not only consistently minimize all affective expression, but also report less pain (50). The 'stoic' groupings with our patient sample reported average or above levels of pain. They can perhaps be best described as 'emotionally stoic'.

Although tempered versions of the general stoic typology were found among both male ( $47 \%$ of sample) and female $(27 \%)$ patients, the 'stoic-prolonged pain' grouping was found to be present only among male patients (7\%). The average age for this group was higher, although the difference was not statistically significant. The grouping of female patients with very long pain duration and significantly higher age (mean 56.3 years; $8 \%$ of sample) had moderate levels of pain, perceived disability and distress. It can be argued that any of the hypothesized contributors to stoicism are more active among men than women. In the present study, the number of patients in the groupings was small, 
and further study is needed before definitive conclusions can be made. There are clearly social mores that differentially reinforce stoicism across genders. Although ethnicity was not examined in our study, some data suggest that subtle ethnic differences exist in stoicism for pain, although many ethnic groups appear to align themselves with stoic traits (51). Ethnic/cultural differences might interact with gender in influencing reports of pain and associated distress.

The results of the present study suggest that the 'good control' grouping, with low levels of pain, perceived disability and distress, is the most robust presentation among chronic pain patients. This cluster grouping has been consistently identified in prior research $(13,19)$ and was revealed in all of the analyses. It accounted for between $20 \%$ and $55 \%$ of the subsamples of patients in the analyses, with approximately equal prevalence among men $(27 \%)$ and women $(21 \%)$, but much greater prevalence among older $(55 \%)$ than younger $(20 \%)$ patients. The pain duration for this grouping was consistently at an average level for the respective subsamples. Prevalence rates for this patient profile in prior research have ranged from $42 \%$ to $57 \%$ in different subsamples $(13,19)$. There are clearly significant numbers of chronic pain patients who achieve low levels of functional impairment and affective distress in association with good pain control. The 'chronic pain syndrome' profile appears to be generally robust, although with multiple variations. It has been consistently identified across studies, and accounted for between $13 \%$ and $37 \%$ of the subsamples in our analyses, consistent with prevalence rates of $16 \%$ to $26 \%$ in prior research $(13,19)$. The relative elevations of pain, perceived disability and distress varied, suggesting different variations of chronic pain syndromes for older and younger adults, men and women. The existence of numerous forms of chronic pain syndromes based on multiple influencing factors has been long recognized (52). The patient groupings labelled 'high impact' and 'moderate' in this and prior research can clearly be considered additional variants of the chronic pain syndrome.

Pain duration has been shown to be an important variable in pain patient classification. Although older patients can have longer duration of pain on average, the potentially low correlation between these variables was demonstrated in this sample. There is clearly greater variability of duration among older patients, resulting in the greater impact of this variable on patient groupings in the older age group. If temporal adjustment or habituation processes play a role in the clinical presentation of chronic pain conditions, then clearly pain duration is a critical factor in classifying patients. Significant differences in the relationships among various dimensions of the pain experience exist at different stages of chronicity. The previously established pattern of an increasing relationship between pain intensity and the behavioural and subjective dimensions of the pain experience with greater chronicity (24) does not appear to be upheld among some older adults. Psychological adjustment processes may be an important factor, although it is likely that neurophysi- ological changes are involved. One theoretical model proposes that increasing chronic pain duration produces progressive dysfunction of endogenous opioid systems, with resulting dysregulation of the interface between cardiovascular and pain regulatory systems (53). This might be one component of complex central nervous system changes that evolve over time in chronic pain conditions. There is growing evidence to support the role of neuroplastic changes, particularly in the limbic system, in the development of pathological pain syndromes (54).

Several factors must be considered when drawing comparisons with the results of Corran et al (13): cultural influences on pain experience and treatment, differences in assessment/treatment settings, slightly different age groupings and use of different measures for dependent variables. The older patient group of Corran et al (6) had lower average pain ratings, lower depression scores and no difference in average pain duration. In the present study, the older patient group had lower average depression scores, longer average pain duration and no difference in pain ratings. The partial replication of findings without controlling for these multiple variables suggests that at least some of the identified clinical presentations for chronic pain patients are fairly robust.

The grouping of older patients labelled by Corran et al (6) as 'positive adaptation to pain' is a variant of the chronic pain syndrome, and differs only slightly from our 'chronic pain syndrome' cluster in the older sample. Differences in the scaling, construct validity or sensitivity of the measures employed could account for these differences. The primary differences in our results (using the three-symptom model) were the absence of the 'high impact' profile and the presence of the 'stoic' profile. One possible explanation for these findings is that, outside of the few robust profiles for chronic pain patients (eg, 'good control' and variants of 'chronic pain syndrome'), various profiles may exist that are specific to particular patient populations or clinical settings. An alternative explanation involves differences in older patient samples. The older sample in this study was younger (mean 69.6 years versus 75.3 years) and arguably healthier. In the study by Corran et al (6), the majority of patients in the older sample were drawn from a geriatric specialty clinic, and it is possible that associated referral biases would result in a higher level of physical pathology. The authors invoked high physical comorbidity as an explanation for the existence of their 'high impact' group, consistent with published data on the profiles of their clinic patients (55). In the present study, older patients were treated in a general multidisciplinary pain centre and may conceivably have had less severe physical comorbidity, although data are not available to substantiate this. Prior research has shown that, after controlling for physical impairment/disability, older age is associated with more positive self-assessments of health (56). Stoic patterns of response to chronic pain could be tempered by high physical comorbidity through its impact on perceived disability and affective distress.

Several interesting findings emerged from the sex comparisons of patient clustering. In addition to the previously 
noted differences, the identification of two unique profiles among female patients is noteworthy. The 'high distress' profile, with low levels of pain, moderate perceived disability and above average distress was a polar opposite of the 'stoic' cluster. It accounted for $12 \%$ of the female patients. The high emotional reactivity of these patients could be attributable to general lability, representing the other end of the spectrum from stoicism. Alternatively, general coping deficits may be involved, with resulting problems of adjustment to chronic pain. The 'persistence' profile (18\% of female subsample) is surprising more for its lack of precedence in prior research. The subgroup of patients with moderate levels of pain and affective distress but low perceived disability is familiar to most pain clinicians. This pattern of behavioural perseverance reflects a type of resiliency, most likely the result of an interaction of personality traits, prior learning experiences and environmental contingencies.

It is possible that different factors affect levels of affective distress in male and female chronic pain patients. For example, levels of depression and anxiety have been found to be associated with history of various traumas in male chronic pain patients, but not in women (57). It is unfortunate that the interaction of age and sex in patient clusterings could not be evaluated in our sample. This is a valuable subject for future research. Sex differences in response to pain appear to be expressed from early childhood (58). The need for additional research on clinical implications of sex- and gender-related differences in pain experiences has been noted (26). Our results support the contention that older women with chronic pain can benefit from the development of tailored assessment and treatment strategies (59).

There are several limitations to this study and factors that affect interpretation of these results. First, older patients were a minority in our sample, a pattern common to general chronic pain management clinics (1). This can result from multiple factors, including population age distribution (46), and age biases in referral, admission and/or treatment processes (2). Second, several of the measures employed may provide suboptimal assessments of the desired domains. Although pain intensity is generally regarded as the most salient dimension of the pain experience (60), it is only one facet of a multidimensional experience. Broader measures such as the McGill Pain Questionnaire (61) used in prior research could influence cluster groupings. Additionally, the measure of perceived disability in this study requires further psychometric evaluation to establish its reliability and validity. Third, the cluster groupings defined by this study have not yet been validated. As Turk and Rudy (38) noted, "one cluster analysis does not a taxonomy make". Although internal validation is feasible (21), it is our opinion that validation of patient clusters is best achieved through replication in independent chronic pain samples. And finally, the subjects in this study represented a very heterogeneous sample of chronic pain patients. It is likely that different patient groupings exist within specific diagnostic subgroups of chronic pain patients (eg, fibromyalgia, migraine headaches, lumbar radiculopathies). Research is needed to evaluate classification systems within homogeneous patient samples.

The primary clinical implication of our findings is the importance of comprehensive assessment for chronic pain patients across the age spectrum, with attention to unique presentations that are found among older patients. A number of important issues involved in the assessment and treatment of older persons with chronic pain are most effectively addressed through a multidisciplinary approach (62). Better understanding of age and sex differences in clinical presentations provides the opportunity for improving assessment and treatment protocols. This requires further research to validate the identified patient groupings and examine the relationships of these groupings to treatment design and outcome. For example, further empirical study of older adults with a stoic presentation for chronic pain may be helpful for enhancing interventions to improve coping abilities. It has been suggested that cognitive psychotherapy, a common component of psychological interventions for chronic pain, has roots in the Stoic philosophies of ancient Rome (63). Also, the significant portion of patients with chronic pain with a 'good control' profile might benefit from more focused and less comprehensive treatment, due to floor effects limiting treatment outcome (64).

The effect of aging on the clinical presentation of chronic pain can only be directly evaluated through longitudinal research. This is a worthy area for future investigation, albeit a challenging one. One of the primary benefits of classification systems is to allow greater individualization of treatment, leading to better outcomes. To date, few studies have evaluated the differential efficacy of treatments tailored to specific profiles of chronic pain, and no classification system has demonstrated utility in predicting treatment outcome (38). This remains an important challenge in the advancement of chronic pain management.

\section{REFERENCES}

1. Harkins SW, Price DD. Assessment of pain in the elderly. In: Turk DC, Melzack R, eds. Handbook of Pain Assessment. New York: Guilford, 1992:315-31.

2. Kee WG, Middaugh SJ, Pawlick KL. Persistent pain in the older patient: Evaluation and treatment. In: Gatchel RJ, Turk DC, eds. Psychological Approaches to Pain Management: A Practitioner's Handbook. New York: Guilford Press, 1996:371-402.

3. Middaugh SJ, Levin RB, Kee WG, Barchiesi FD, Roberts JM. Chronic pain: Its treatment in geriatric and younger patients. Arch Phys Med Rehabil 1988;69:1021-6.

4. Sorkin BA, Rudy TE, Hanlon RB, Turk DC, Stieg RL. Chronic pain

in old and young patients: Differences appear less important than similarities. J Gerontol 1990;45:P64-8.

5. Keefe FJ, Williams DA. A comparison of coping strategies in chronic pain patients in different age groups. J Gerontol 1990;45:P161-5.

6. Corran TM, Gibson SJ, Farrell MJ, Helme RD. Comparison of chronic pain experience between young and elderly patients. In: Gebhart GF, Hammond DL, Jensen TS, eds. Proceedings of the VIIth World Congress on Pain. Seattle: IASP Press, 1994:895-906.

7. Benbow SJ, Cossins L, Bowsher D. A comparison of young and elderly patients attending a regional pain center. Pain Clin 1995;8:323-32. 
8. Turk DC, Okifuji A, Scharff L. Chronic pain and depression: Role of perceived impact and perceived control in different age cohorts. Pain 1995;61:93-101.

9. Buckelew SP, Shutty MS, Hewett J, Landon T, Morrow K, Frank R. Health locus of control, gender differences, and adjustment to persistent pain. Pain 1990;42:287-94.

10. Gibson SJ, Helme RD. Cognitive factors and the experience of pain and suffering in older persons. Pain 2000;85:375-83.

11. Riley JL, Wade JB, Robinson ME, Price DD. The stages of pain processing across the adult lifespan. J Pain 2000;1:162-70.

12. Cutler RB, Fishbain DA, Rosomoff RS, Rosomoff HL. Outcomes in treatment of pain in geriatric and younger age groups. Arch Phys Med Rehabil 1994;75:457-64.

13. Corran TM, Farrell MJ, Helme RD, Gibson SJ. The classification of patients with chronic pain: Age as a contributing factor. Clin J Pain 1997; 13:207-14.

14. Turk DC, Rudy TE. Towards a comprehensive assessment of chronic pain patients: A multiaxial approach. Behav Res Ther 1987;25:237-49.

15. Keefe FJ, Bradley LA, Crisson JE. Behavioral assessment of low back pain: Identification of pain behavior subgroups. Pain 1990;40:153-60.

16. Jamison RN, Rock DL, Parris WCV. Empirically derived symptom checklist 90 subgroups of chronic pain patients: a cluster analysis. J Behav Med 1988;11:147-58.

17. Shutty MS, DeGood DE. Cluster analyses of responses of low-back pain patients to the SCL-90: comparison of empirical versus rationally derived subscales. Rehabil Psychol 1987;32:133-44.

18. Love AW, Peck CL. The MMPI and psychological factors in chronic low back pain: a review. Pain 1987;28:1-12.

19. Klapow JC, Slater MA, Patterson TL, Doctor JN, Atkinson JH, Garfin SR. An empirical evaluation of multidimensional clinical outcome in chronic low back pain patients. Pain 1993;55:107-18.

20. Aldenderfer MS, Blashfield RK. Cluster analysis. In: Lewis-Beck MS, ed. Quantitative Applications in the Social Sciences. Newbury Park: Sage, 1984.

21. Milligan GW, Cooper MC. Methodology review: clustering methods. Appl Psychol Meas 1987;11:329-54.

22. Hinkley BS, Jaremko ME. Effects of pain duration on psychosocial adjustment in orthopedic patients: the importance of early diagnosis and treatment of pain. J Pain Symptom Manage 1994;9:175-85.

23. Wittenauer DA. Psychological and demographic variables related to duration of pain in chronic pain syndrome. Dissertation Abstr Int 1988;49:1414.

24. Zarkowska E, Philips HC. Recent onset vs. persistent pain: evidence for a distinction. Pain 1986;25:365-72.

25. Berkley KJ. Sex differences in pain. Behav Brain Sci 1997;20:371-80.

26. Fillingim RB. Sex-related differences in the experience of pain. Am Pain Soc Bull 2000;10:1-15.

27. Jensen MP, Karoly P. Self-report scales and procedures for assessing pain in adults. In: Turk DC, Melzack R, eds. Handbook of Pain Assessment. New York: Guilford Press, 1992:135-51.

28. Jensen MP, Karoly P, Braver S. The measurement of clinical pain intensity: a comparison of six methods. Pain 1986;27:117-26.

29. Pollard CA. Preliminary validity study of the pain disability index. Percept Mot Skills 1984;59:974.

30. Tait RC, Chibnall JT, Krause S. The pain disability index: psychometric properties. Pain 1990;40:171-82.

31. Kerns RD, Jacob MC. Assessment of the psychosocial context of the experience of chronic pain. In: Turk DC, Melzack R, eds. Handbook of Pain Assessment. New York: Guilford Press, 1992:235-53.

32. Derogatis L. The SCL-90R manual - II: administration, scoring and procedures. Baltimore: Clinical Psychometric Research, 1983.

33. Shutty MS, DeGood DE, Schwartz DP. Psychological dimensions of distress in chronic pain patients: a factor analytic study of symptom checklist-90 responses. J Consult Clin Psychol 1986;54:836-42.

34. Buckelew SP, Burk JP, Brownlee-Duffeck M, Frank RG, DeGood DE. Cognitive and somatic aspects of depression among a rehabilitation sample: reliability and validity of SCL-90-R research subscales. Rehabil Psychol 1988;33:67-75.

35. Butler RN. Geriatrics. In: Maddox GL, ed. The Encyclopedia of Aging. New York: Springer, 1987:284

36. Ward JH. Hierarchical grouping to optimize an objective function J Am Stat Assoc 1963;58:236-44.
37. Overall JE, Gibson JM, Novy DM. Population recovery capabilities of 35 cluster analysis methods. J Clin Psychol 1993:49:459-70.

38. Turk DC, Rudy TE. Classification logic and strategies in chronic pain. In: Turk DC, Melzack R, eds. Handbook of pain assessment. New York: Guilford Press, 1992:409-28.

39. Sarle WS. The number of clusters. Cary: SAS Institute, 1996.

40. Calinski T, Harabasz J. A dendrite method for cluster analysis. Commun Stat 1974;3:1-27.

41. Duda RO, Hart PE. Pattern classification and scene analysis. New York: John Wiley \& Sons, 1973.

42. Sarle WS. Cubic clustering criterion. Cary: SAS Institute Inc, 1983

43. Harkins SW, Lagua B, Price DD, Small RE. Geriatric pain. In: Roy R, ed. Chronic Pain in Old Age: An Integrated Biopsychosocial Perspective. Toronto: University of Toronto Press, 1995:127-63

44. Gibson SJ, Katz B, Corran TM, Farrell MJ, Helme RD. Pain in older persons. Disabil Rehabil 1994;16:127-39.

45. Cook AJ, Thomas MR. Pain and the use of health services among the elderly. J Aging Health 1994;6:155-72.

46. Gagliese L, Melzack R. The assessment of pain in the elderly. In: Mostofsky D, Lomranz J, eds. Handbook of Pain and Aging. New York: Plenum Press, 1997:69-96.

47. Gibson SJ. The measurement of mood states in older adults. J Gerontol 1997;52B:P167-74.

48. Melding PS. Coping with pain in old age. In: Mostofsky DI, Lomranz J, eds. Handbook of Pain and Aging. New York: Plenum Press, 1997:167-84.

49. Large R, Strong J. The personal constructs of coping with chronic low back pain: is coping a necessary evil? Pain 1997:73:245-52.

50. Janal MN. Pain sensitivity, exercise and stoicism. J R Soc Med 1996;89:376-81.

51. Lipton JA, Marbach JJ. Ethnicity and the pain experience. Soc Sci Med 1984;19:1279-98.

52. Tunks E. Is there a chronic pain syndrome? In: Lipton, ed. Advances in Pain Research and Therapy, 13th edn. New York: Raven Press, 1990:257-66.

53. Bruehl S, McCubbin JA, Harden RN. Theoretical review: altered pain regulatory systems in chronic pain. Neurosci Biobehav Rev 1999;23:877-90.

54. Rome HP, Rome JD. Limbically augmented pain syndrome (LAPS): Kindling, corticolimbic sensitization, and the convergence of affective and sensory symptoms in chronic pain disorders. Pain Med 2000;1:7-23

55. Helme RD, Bradbeer M, Katz B, Gibson SJ. Management of chronic, nonmalignant pain in the elderly: experience in an outpatient setting. In: Mostofsky D, Lomranz J, eds. Handbook of Pain and Aging. New York: Plenum Press, 1997:241-66.

56. Mutran E, Ferraro KF. Medical need and use of services among older men and women. J Gerontol 1988:43:S162-71.

57. Spertus IL, Burns J, Glenn B, Lofland K, McCracken L. Gender differences in associations between trauma history and adjustment among chronic pain patients. Pain 1999;82:97-102.

58. Lamberg L. Girls' and boys' differing response to pain starts early in their lives. JAMA 1998;280:1035-7.

59. Roberto KA, ed. Older Women with Chronic Pain. New York: Haworth: Harrington Park Press, 1994.

60. Turk DC, Melzack R. The measurement of pain and the assessment of people experiencing pain. In: Turk DC, Melzack R, eds. Handbook of Pain Assessment. New York: Guilford Press, 1992:3-12.

61. Melzack R. The McGill Pain Questionnaire: major properties and scoring methods. Pain 1975;1:277-99.

62. Cook AJ, ed. Pain assessment and management: multidisciplinary approaches. Top Geriatr Rehabil 2001;16.

63. Montgomery RW. The ancient origins of cognitive therapy: the reemergence of stoicism. J Cogn Psychother 1993;7:5-19.

64. Turk DC, Okifuji A, Sinclair JD, Starz TW. Differential responses by psychosocial subgroups of fibromyalgia syndrome patients to an interdisciplinary treatment. Arthritis Care Res $1998 ; 11: 397-404$ 


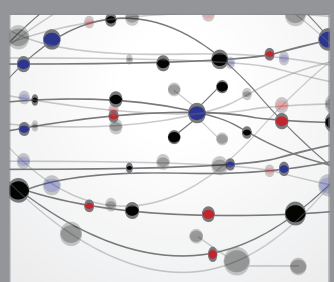

The Scientific World Journal
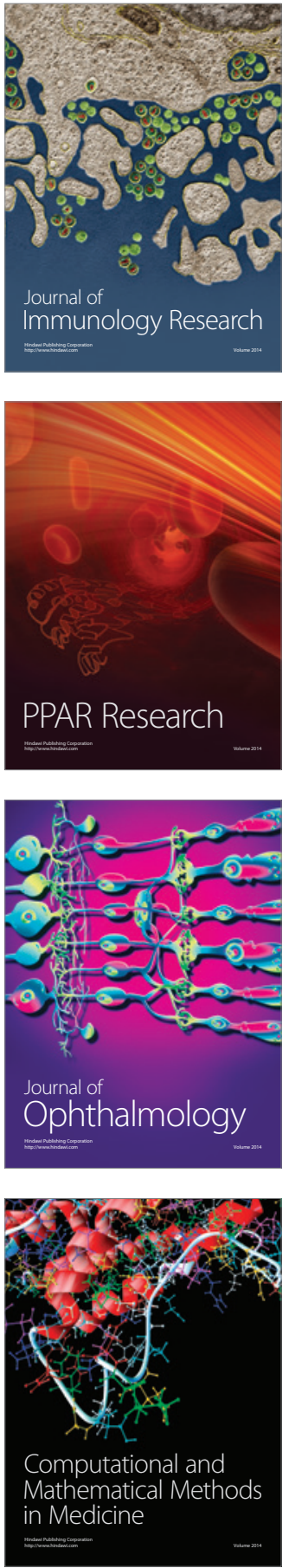

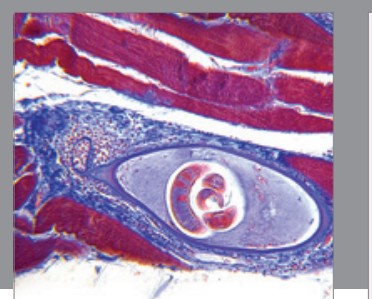

Gastroenterology Research and Practice

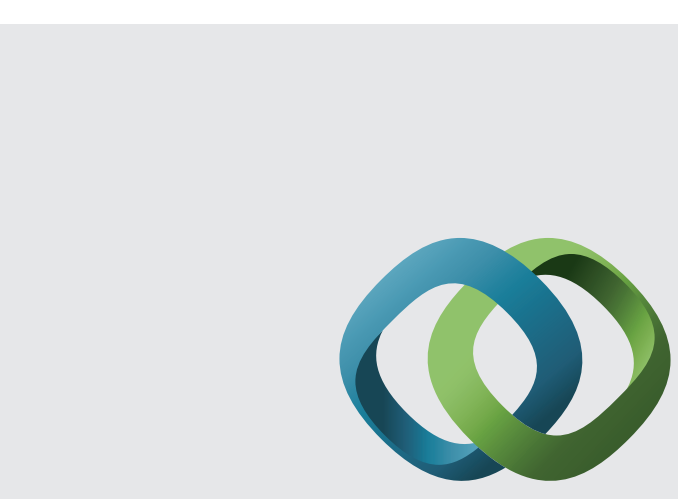

\section{Hindawi}

Submit your manuscripts at

http://www.hindawi.com
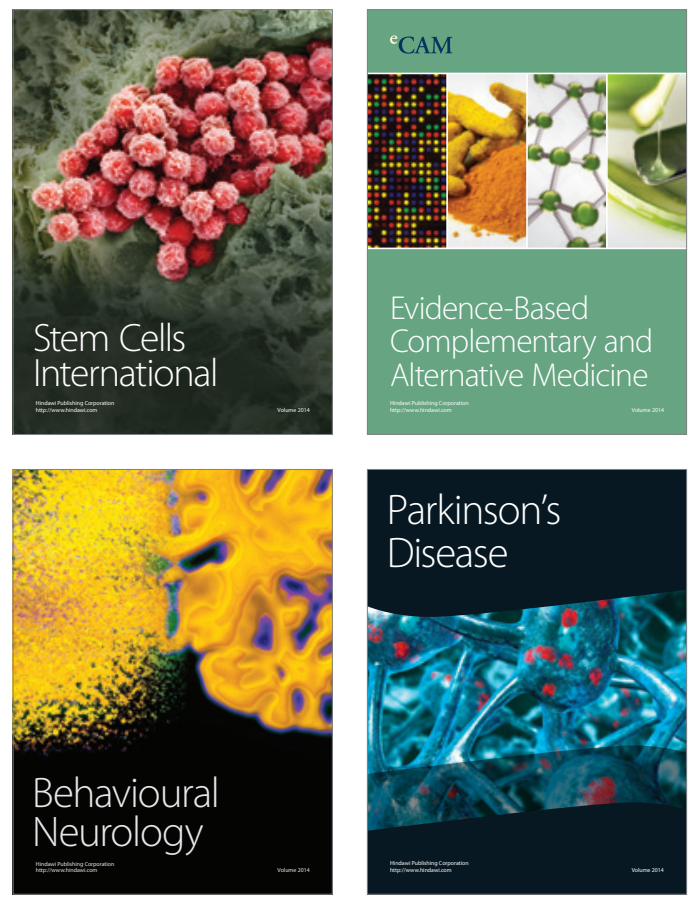
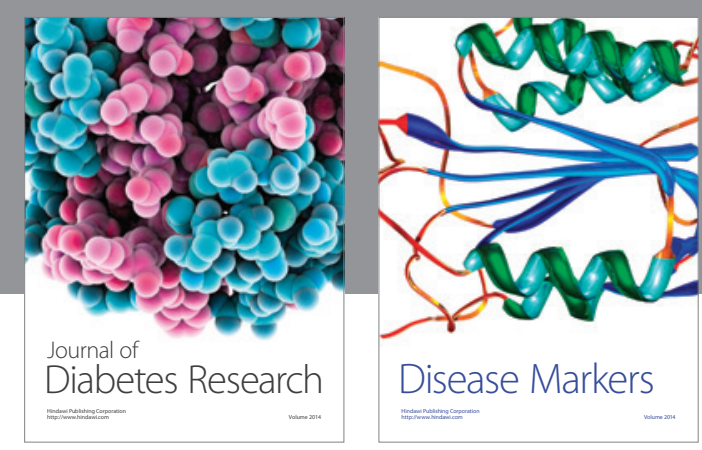

Disease Markers
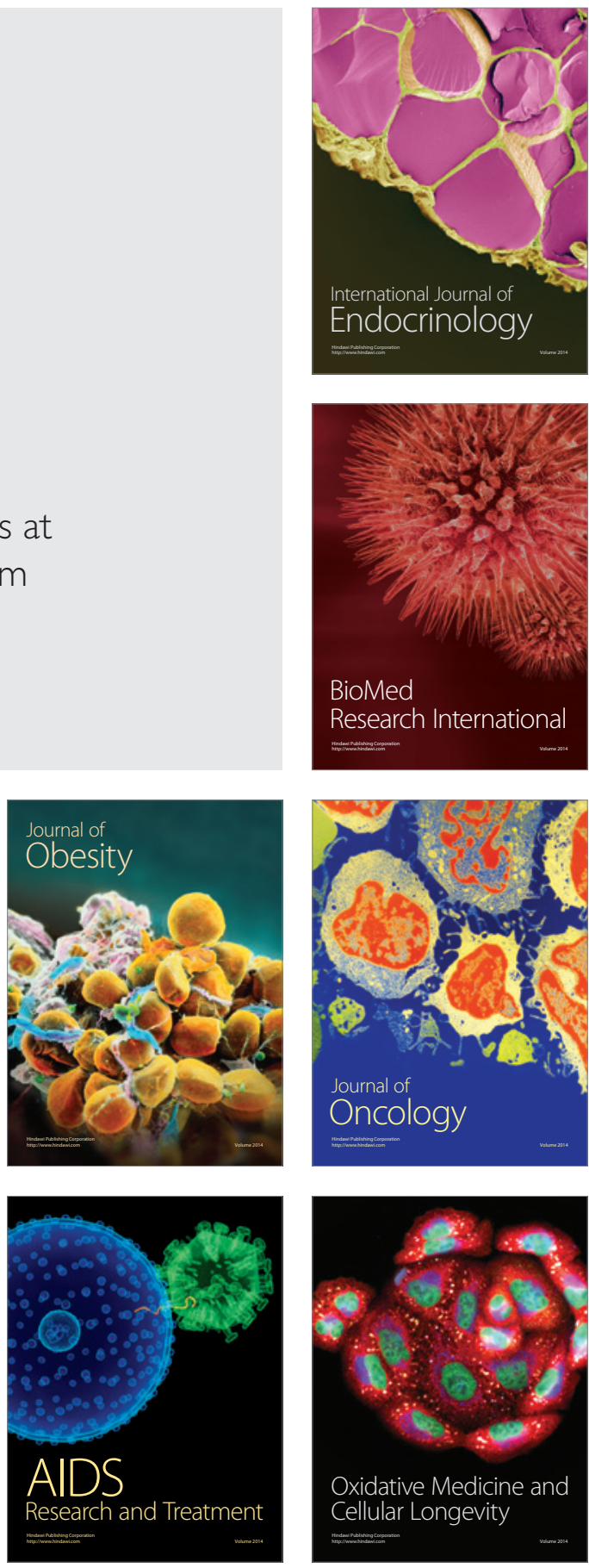